\title{
Synthesis and evaluation of cyclic sulfite diesters as sulfur dioxide $\left(\mathrm{SO}_{2}\right)$ donors
}

\author{
Satish R. Malwal ${ }^{\dagger}$, Kundansingh Pardeshi, Harinath Chakrapani ${ }^{\star}$
}

\begin{abstract}
Although sulfur dioxide $\left(\mathrm{SO}_{2}\right)$ finds widespread use in the food industry as its hydrated form, sulfite, a number of aspects of $\mathrm{SO}_{2}$ biology remain to be completely understood. Among the tools available for intracellular enhancement of $\mathrm{SO}_{2}$, most suffer from poor cell permeability and a lack of control over $\mathrm{SO}_{2}$ release. We report 1,2-cyclic sulfite diesters as a new class of reliable $\mathrm{SO}_{2}$ donors that dissociate in buffer through a nucleophilic displacement to produce $\mathrm{SO}_{2}$ with tuneable release profiles. We provide data in support of the suitability of these $\mathrm{SO}_{2}$ donors to enhance intracellular levels of $\mathrm{SO}_{2}$ at an efficiency superior to sodium bisulfite, the most commonly used $\mathrm{SO}_{2}$ donor for cellular studies.
\end{abstract}

\section{Introduction}

Sulfur dioxide $\left(\mathrm{SO}_{2}\right)$ is an environmental pollutant that is also produced during metabolism of sulfur containing amino acids ${ }^{[1]}$ as well as hydrogen sulfide $\left(\mathrm{H}_{2} \mathrm{~S}\right)$, which is known to mediate a number of cellular processes. ${ }^{[2]}$ The known vasodilatory effects of $\mathrm{SO}_{2}$ in animal models suggest possible signaling roles for this gas as well. ${ }^{[3]} \mathrm{SO}_{2}$ is also used in the food industry as a preservative and an anti-bacterial agent. ${ }^{[4]}$ At elevated levels $\mathrm{SO}_{2}$ is known to cause biomacromolecular damage and cell death; ${ }^{[5]}$ these damaging effects are perhaps responsible for the anti-bacterial properties of this gas. However, due to the limited understanding of molecular mechanisms of action of this gas, reliably producing ${ }^{[6]}$ and detecting $\mathrm{SO}_{2}$ within cells are necessary. While there are numerous probes for $\mathrm{SO}_{2}$, biological studies have thus far relied on gaseous $\mathrm{SO}_{2}$ or a complex formulation of inorganic sulfites ${ }^{[7]}$ Both methods may not be well suited for enhancing $\mathrm{SO}_{2}$ within cells and offer no temporal control over $\mathrm{SO}_{2}$ release. Furthermore, they are useful for studying effects of $\mathrm{SO}_{2}$ as a single dose, which is unsuitable for study of prolonged exposure. Thus, the chemical biology of $\mathrm{SO}_{2}$ remains largely uncharacterized. ${ }^{15}$ Our laboratory has developed several strategies having different triggers for generating $\mathrm{SO}_{2}$ under physiological conditions using small organic molecules. ${ }^{[8]}$ First, 2,4-dinitrophenylsulfonamides with tunable rates of generation of $\mathrm{SO}_{2}$ when triggered by biological thiols were reported (Scheme 1). The use of thiol is used as a trigger may complicate biological studies as targets of $\mathrm{SO}_{2}$ include biologically relevant disulfides and thiols. ${ }^{[8 a, 8 b, 9]}$ In a second strategy, a series of benzosultines as $\mathrm{SO}_{2}$ donors with controlled rate of generation of $\mathrm{SO}_{2}$ under

Indian Institute of Science Education and Research Pune, Dr. Homi Bhabha Road, Pashan Pune 411 008, Maharashtra, India

${ }^{\dagger}$ Present address: Department of Chemistry, University of Illinois at Urbana-Champaign, Urbana, IL 61801, USA

* Corresponding author. Tel.: +91-20-2590-8090; fax: +91-20-25899790; e-mail: harinath@iiserpune.ac.in

Supporting information for this article is given via a link at the end of the document physiological condition, having heat as a trigger was reported (Scheme 1). ${ }^{[8 c]}$ Although enzosultines are stable as solids, they are not highly suited for prolonged storage at room temperature as stock solutions. In third strategy, benzosulfones were reported as photochemically activated $\mathrm{SO}_{2}$ donors by our group and others (Scheme 1). ${ }^{[8 \mathrm{~d}]}$ These compounds might have limitations associated with the inconvenience associated with using a light source in cellular studies and possibly by intensity of light that was required for $\mathrm{SO}_{2}$ generation. ${ }^{[10]}$ Xian et al. reported sodium benzothiazole sulfonate as water-soluble $\mathrm{SO}_{2}$ donor, having limitation of prolonged half-life ( $\mathrm{t}_{1 / 2}=13$ days) at physiological $\mathrm{pH}$ 7.4. ${ }^{[11]}$ Recently, $\mathrm{SO}_{2}$ donors, using esterase as a trigger, ${ }^{[8 f,}{ }^{12]}$ and click reaction as a mode of $\mathrm{SO}_{2}$ donation, have been reported by our, and Wang's group (Scheme 1). These strategies rely on the use of cellular enzyme, and bio-orthogonal reaction.

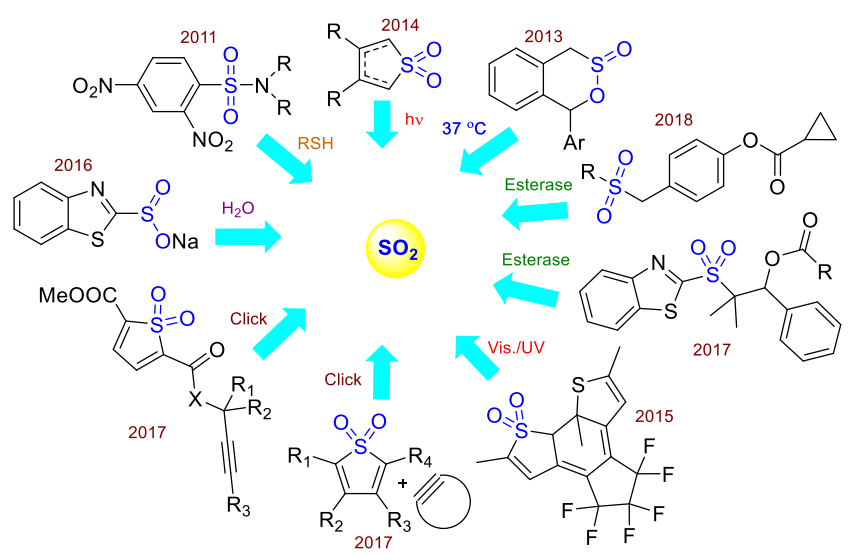

Scheme 1. Reported strategies for generation of $\mathrm{SO}_{2}$ under physiological conditions.

Therefore, new self-emulative $\mathrm{SO}_{2}$ donors which are stable at room temperature and permeate cells to enhance intracellular $\mathrm{SO}_{2}$ could help better understand cellular responses to this important gaseous molecule.

\section{Results and Discussion}

1,2-Cyclic sulfite diesters were considered as $\mathrm{SO}_{2}$ donors (Scheme 2). Upon attack by a nucleophile (such as water), a sulfite monoester would be formed, which could spontaneously decompose to produce $\mathrm{SO}_{2}$. Modulating substituents "R" or perhaps the $p K_{\mathrm{a}}$ of the leaving group would help tune the rate of substitution by a nucleophile and possibly $\mathrm{SO}_{2}$ release. Here, we report results of synthesis and evaluation of a series of 1,2-cyclic sulfite diesters as $\mathrm{SO}_{2}$ donors. 


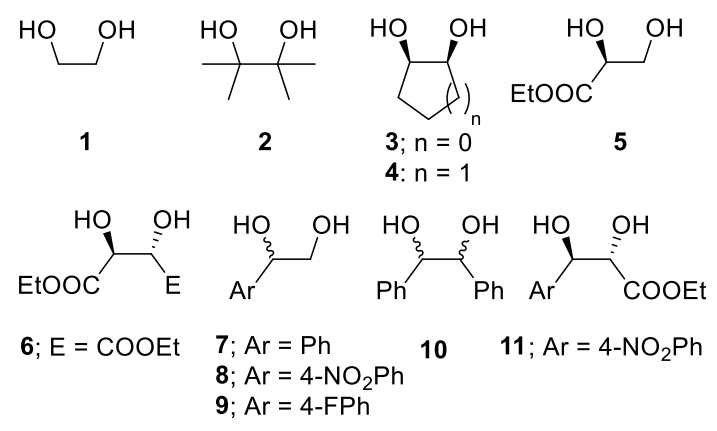

Figure 1. 1,2-diols prepared for synthesis of 1,2-cyclic sulfite diesters.

1,2-diols used for synthesis of 1,2-cyclic sulfite diesters were either commercially available (1 and 2; Figure 1) or prepared by Upjohn dihydroxylation from corresponding olefin by $\mathrm{OsO}_{4}$ mediated dihydroxylation ${ }^{[13]}$ (diols 3-5 and 11; Figure 1) or by nucleophilic ring opening of 4 -substituted styrene oxide by $10 \%$ aq. $\mathrm{K}_{2} \mathrm{CO}_{3}$ solution. The diol 6 and $\mathbf{1 0}$ were synthesized from Ltartaric acid, and $\mathrm{NaBH}_{4}$ mediated reduction ${ }^{[14]}$ of $( \pm)$-benzoin respectively. The diols 7 and 8-9 were prepared by ring opening of corresponding $( \pm)$-phenyloxirane and substituted ( \pm )phenyloxirane, in $10 \% \mathrm{~K}_{2} \mathrm{CO}_{3}$ reflux condition respectively. Various 1,2 -cyclic sulfite diesters $\mathbf{( 1 2 - 2 2 )}$ were prepared by the reaction of 1,2-diols with thionyl chloride, triethylamine and imidazole in DCM at $0{ }^{\circ} \mathrm{C}$ (Table 1). ${ }^{[15]}$ The cis-1,2-diols 3 and $\mathbf{4}$, gave an isomeric mixture (depending on sulfoxide orientation) of 14 (1:0.68), 15 (1:0.64) by ${ }^{1} \mathrm{H}$ NMR. ${ }^{[16]}$ The diols 5, 6 and 11 afforded mixture of diastereomers of 16,17 and 18 in the ratios (depending on chirality of sulfoxide), 16 (1:0.95), 17 ( 1:1) and 22 (1:0.86) by ${ }^{1} \mathrm{H}$ NMR. The racemic 1,2 -diols $7-10$ afforded mixture of diastereomers for 18-21.

The aforementioned derivatives 12-22 were evaluated for $\mathrm{SO}_{2}$ release in $\mathrm{pH} 7.4$ phosphate buffer. First, ethylene glycol derivative 12 was incubated at $37^{\circ} \mathrm{C}$ in $\mathrm{pH} 7.4$ buffer for $30 \mathrm{~min}$. The reaction was monitored for $\mathrm{SO}_{2}$ generation by ion chromatography equipped with an ion conductivity detector; ${ }^{\left[{ }^{[b]}\right]}$ $\mathrm{SO}_{2}$ was quantified as sulfite, $\mathrm{SO}_{3}{ }^{2-}$. After $30 \mathrm{~min}, 12$ gave $45 \%$ of $\mathrm{SO}_{2}$ (Table 2, entry 1 ). The pinacol derivative $\mathbf{1 3}$ produced negligible amounts of $\mathrm{SO}_{2}$ and a $2 \%$ yield was recorded (Table 2 , entry 2). These results suggest that increasing sterics on the carbon bearing the sulfite functional group reduced the propensity for decomposition of the compound supporting direct displacement at the carbon, which involves formation of a sulfite monoester, which in turn rapidly rearranges to produce $\mathrm{SO}_{2}$ and an alcohol (Scheme 2)
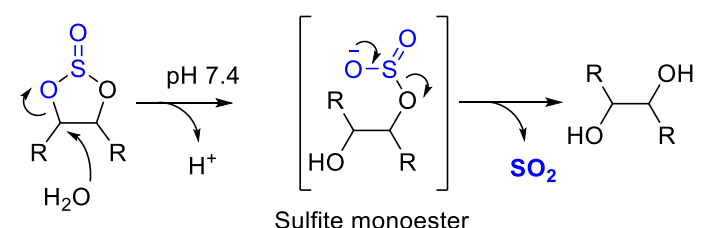

Scheme 1. Sulfite diesters can decompose in $\mathrm{pH} 7.4$ buffer to produce $\mathrm{SO}_{2}$.
Table 1. Synthesis of 1,2-cyclic sulfite diesters.

$$
\underset{\substack{\mathrm{O} \\ 0^{\circ} \mathrm{C}, 3 \text { to } 6 \mathrm{~h}}}{\stackrel{\mathrm{SOCl}_{2}, \mathrm{NEt}_{3}}{\mathrm{Omidazole}, \mathrm{DCM}}}
$$

\begin{tabular}{|c|c|c|c|c|c|c|c|}
\hline Entry & $\mathrm{R}^{1}$ & $\mathrm{R}^{2}$ & $\mathrm{R}^{3}$ & $\mathrm{R}^{4}$ & Diol & Prod & $\begin{array}{l}\text { Yield } \\
(\%)\end{array}$ \\
\hline 1 & $-\mathrm{H}$ & $-\mathrm{H}$ & $-\mathrm{H}$ & $-\mathrm{H}$ & 1 & 12 & 78 \\
\hline 2 & $-\mathrm{CH}_{3}$ & $-\overline{\mathrm{CH}_{3}}$ & $-\mathrm{CH}_{3}$ & $-\overline{\mathrm{CH}_{3}}$ & 2 & 13 & 96 \\
\hline 3 & $-\left(\mathrm{CH}_{2}\right)_{3^{-}}$ & $-H$ & ${ }^{-}\left(\mathrm{CH}_{2}\right)_{3}-$ & $-H$ & 3 & 14 & 90 \\
\hline 4 & $-\left(\mathrm{CH}_{2}\right)_{4-}$ & $-H$ & ${ }^{-}\left(\mathrm{CH}_{2}\right)_{4^{-}}$ & $-H$ & 4 & 15 & 69 \\
\hline 5 & -COOEt & $-H$ & $-H$ & $-H$ & 5 & 16 & 87 \\
\hline 6 & -COOEt & $-H$ & $\overline{\text { COOEt }}$ & $-H$ & 6 & 17 & 80 \\
\hline 7 & $-P h$ & $-H$ & $-H$ & $-H$ & 7 & 18 & 93 \\
\hline 8 & $4-\mathrm{NO}_{2}-\mathrm{Ph}-$ & $-H$ & $-H$ & $-H$ & 8 & 19 & 81 \\
\hline 9 & 4-F-Ph- & $-H$ & $-H$ & $-H$ & 9 & 20 & 75 \\
\hline 10 & $-\mathrm{Ph}$ & $-H$ & $-\mathrm{Ph}$ & $-H$ & 10 & 21 & 86 \\
\hline 11 & $4-\mathrm{NO}_{2}-\mathrm{Ph}-$ & $-H$ & COOEt & $-H$ & 11 & 22 & 75 \\
\hline
\end{tabular}

In the cases of $12-15$, nearly similar $\mathrm{p} K_{\mathrm{a}}$ values for the alcohols implies that any difference in $\mathrm{SO}_{2}$ yields must be due to increased steric hinderance at the carbon bearing the sulfite ester. The diesters 12, 14 and 15 gave $\mathrm{SO}_{2}$ yields $>20 \%$ after $30 \mathrm{~min}$, whereas pinacol derivative $\mathbf{1 3}$ gave $2 \%$ of $\mathrm{SO}_{2}$. These results suggest that when leaving group was similar the important determinant of observed reaction rates was sterics supporting the proposed mechanism (Scheme 2). These results are also consistent with previous reports ${ }^{[17]}$ of 1,2-cyclic sulfite diesters undergoing nucleophilic substitution with various nucleophiles such as chloride, azide and $\left(\mathrm{CH}_{3} \mathrm{OOC}\right)_{2} \mathrm{HC}^{-}$at one of the activated carbon atoms (Scheme 2). ${ }^{[17-18]}$ The hydrolysis of cyclic sulfite esters of normal, or cis or trans diols under acidic (cat. $\mathrm{H}_{2} \mathrm{SO}_{4} / \mathrm{HClO}_{4}$ ) or basic (2 eq. $\mathrm{NaOH}$ ) reflux condition, results in sulfur-oxygen bond fission to give corresponding diol without change in stereo-configuration. ${ }^{[17,19]}$

In order to study the electronic effect on decomposition, diesters 16 and 17 were incubated in $\mathrm{pH} 7.4$ buffer and $93 \%$ and $98 \% \mathrm{SO}_{2}$, respectively were recorded (Table 2 , entry 5 and 6). These compounds contain an electron withdrawing substituent as compared to ethylene glycol diester 12. The electron withdrawing nature of the ester enhances electrophilicity of the carbon bearing the sulfite functional group contributing to an increased rate of displacement.

Next, decomposition of derivatives with phenyl substituent 18-21 was carried out. After $30 \mathrm{~min}$, the phenyl derivative 18 gave $73 \%$ of $\mathrm{SO}_{2}$ (Table 2, entry 7 ). The $4-\mathrm{NO}_{2}$ - phenyl derivative 19 on the other hand produced higher amount of $\mathrm{SO}_{2}$ and a $96 \%$ yield was obtained (Table 2, entry 8). Incubation of the 4-F-phenyl derivative 20 (Table 2, entry 9 ) resulted in a nearly similar $\mathrm{SO}_{2}$ yield as that of phenyl derivative 18. The diphenyl derivative $\mathbf{2 1}$ gave $83 \% \mathrm{SO}_{2}$ after $30 \mathrm{~min}$ (Table 2, entry 10). These results 
suggest that electron withdrawing group on phenyl substituent increases the rate of decomposition, again consistent with a nucleophilic displacement mechanism.

Table 2. Sulfur dioxide yields and calculated $\mathrm{p} K_{\mathrm{a}}$ s of 1,2-diols

\begin{tabular}{llll}
\hline Entry & Compd & $\% \mathrm{SO}_{2}$ yield after $30 \mathrm{~min}$ & $\mathrm{p} K_{\mathrm{a}}^{\mathrm{a}}$ \\
\hline 1 & $\mathbf{1 2}$ & 45 & 14.40 \\
2 & $\mathbf{1 3}$ & 2 & 14.23 \\
3 & $\mathbf{1 4}$ & 25 & 14.25 \\
4 & $\mathbf{1 5}$ & 21 & 14.27 \\
5 & $\mathbf{1 6}$ & 93 & 11.91 \\
6 & $\mathbf{1 7}$ & 98 & 10.64 \\
7 & $\mathbf{1 8}$ & 73 & 13.83 \\
8 & $\mathbf{1 9}$ & 96 & 13.48 \\
9 & $\mathbf{2 0}$ & 68 & 13.73 \\
10 & $\mathbf{2 1}$ & 83 & 13.70 \\
11 & $\mathbf{2 2}$ & 95 & 11.53 \\
\hline
\end{tabular}

${ }^{a}$ Values are for the corresponding 1,2-diol (most acidic proton) calculated using ChemBioDraw Ultra 16.0.

A number of $\mathrm{SO}_{2}$ probes that typically use the distinct nucleophilic properties of sulfite/bisulfite have been developed by various groups. ${ }^{[20]}$. For example, Sun et al. have reported probe 23 for selective detection of $\mathrm{SO}_{2}$ derivatives $\mathrm{HSO}_{3}-\mathrm{SO}_{3}{ }^{2-}$ in $\mathrm{pH} 7.4$ buffer (Scheme 3). ${ }^{[20 c]}$ The probe 23 absorbs at $545 \mathrm{~nm}$ and upon reaction with $\mathrm{HSO}_{3}-\mathrm{SO}_{3}{ }^{2-}$, a distinct and ratiometric shift to an absorbance at $410 \mathrm{~nm}$ (for 24) was observed (see Supporting Information, Figures S1 and S2). A similar UV profile was observed when 23 was reacted with the $\mathrm{SO}_{2}$ donor 17 supporting the intermediacy of sulfite (Figure 2a). The probe 23 fluoresces in the red region and upon reaction with $\mathrm{SO}_{3}{ }^{2-} / \mathrm{HSO}_{3}{ }^{-}$it forms green fluorescing adduct 24 (Figure $2 b$ ). When 23 was treated with sulfite diester 17, we find a similar shift in emission (Figure $2 b$ ). Together, these data independently confirm the ability of $\mathbf{1 7}$ to generate $\mathrm{SO}_{2}$ in $\mathrm{pH} 7.4$ buffer.

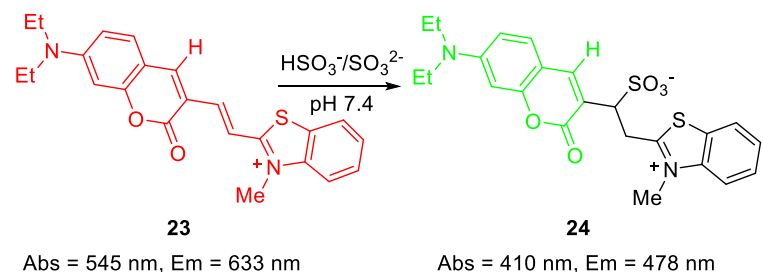

Scheme 3. Reaction of probe $\mathbf{2 3}$ with sulfites

The expected product formed during hydrolysis in buffer is the diol (Scheme 2). In order to confirm this, we incubated 19 in $\mathrm{pH} 7.4$ buffer and monitored the decomposition and formation of 1-(4-nitrophenyl)ethane-1,2-diol 8 (Figure 3). We find nearly complete disappearance of $\mathbf{1 9}$ during $30 \mathrm{~min}$ with the formation of
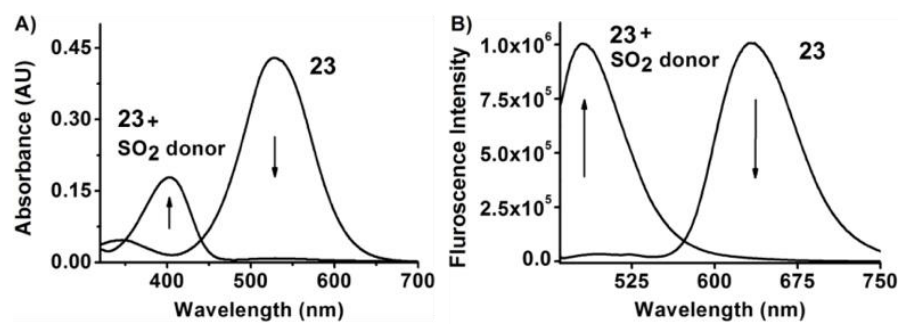

Figure 2. (A) UV-vis spectra of probe $(10 \mu \mathrm{M})$ in presence of $100 \mu \mathrm{M}$ of 17 in $\mathrm{pH} 7.41 \%$ DMSO/PB. (B) Fluorescence spectra of probe $(10 \mu \mathrm{M})$ in presence of $100 \mu \mathrm{M}$ of $\mathbf{1 7}$ in $\mathrm{pH} 7.41 \% \mathrm{DMSO} / \mathrm{PB}$.

8 as the exclusive product (Figure 3 ) and a nearly quantitative yield of $\mathrm{SO}_{2}$ (Table 2, entry 8 ). Thus, the decomposition of the sulfite monoester was rapid and $\mathrm{SO}_{2}$ is likely to be generated as soon as the intermediate is produced (Scheme 2).

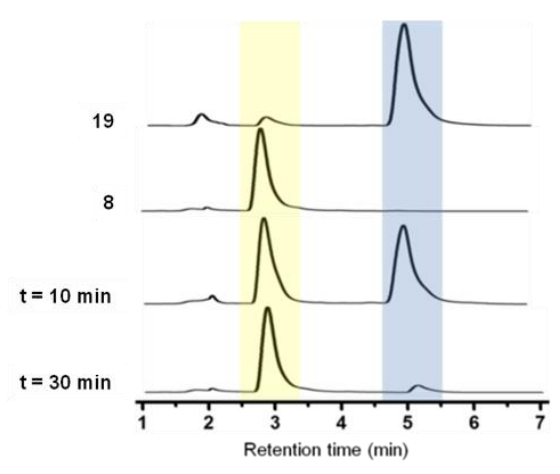

Figure 3. Decomposition of 19 in $\mathrm{pH} 7.4$ 1\% DMSO/PB was monitored by HPLC, $1: 1 \mathrm{ACN} / \mathrm{H}_{2} \mathrm{O}$ isocratic gradient, wavelength, $\lambda=254 \mathrm{~nm}$. During $30 \mathrm{~min}$, nearly complete decomposition of $\mathbf{1 9}$ with concomitant formation of $\mathbf{8}$ was observed.

Having established the suitability of cyclic sulfite esters for molecular biology studies, cell permeability as well as the suitability of these compounds for enhancing intracellular levels of $\mathrm{SO}_{2}$ was examined. The ratiometric probe $\mathbf{2 3}$ has been previously reported to be suitable for detection of intracellular sulfite/bisulfite. When DLD-1 cells treated with $23(10 \mu \mathrm{M})$, we found a distinct fluorescence signal only in the red channel but not in the green channel (Figure 4A-C). ${ }^{[20 c]}$

When cells pre-treated with 23 were exposed to $17(20 \mu \mathrm{M})$, a decrease in fluorescence signal in the red channel with concomitant increase in fluorescence increase in green channel was observed (Figure 4D-F). Under similar conditions, when a similar experiment was conducted with authentic bisulfite, we found a similar profile. ${ }^{[20 c]}$ However, an increased concentration of $200 \mu \mathrm{M}$ was necessary to elicit this response whereas with the donor developed in this study, a significantly lower concentration could achieve enhancement of intracellular $\mathrm{SO}_{2}$. Above results suggest the compatibility of cyclic sulfite diesters with cellular nucleophiles. Lastly, a cell viability assay conducted with human cervical cancer cells (HeLa) revealed $\mathrm{SO}_{2}$ donors 17 and 13 were not significant inhibitors of proliferation at $100 \mu \mathrm{M}$ (see Supporting Information, Figures S3 and S4). Thus, the $\mathrm{SO}_{2}$ donor 17 might find convenient use for studying cellular responses to enhanced reactive sulfur species. 

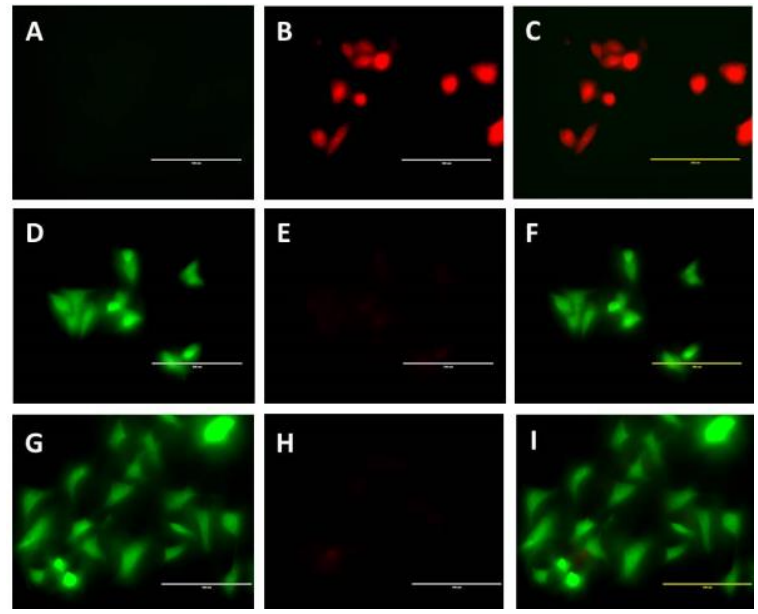

Figure 4. Live cell imaging carried out with DLD-1 cells $(A)$ cells incubated with probe $23(10 \mu \mathrm{M})$ from the green channel; $(B)$ imaging of $(A)$ from the red channel; $(C)$ overlay of $(A)$ and $(B) ;(D)$ fluorescence imaging of cells incubated with probe $23(10 \mu \mathrm{M})$ for $30 \mathrm{~min}$, and further incubated with $17(20 \mu \mathrm{M})$ for 30 min from the green channel; (E) fluorescence imaging of (D) from the red channel; $(F)$ overlap of $(D)$ and $(E) ;(G)$ fluorescence imaging of cells incubated with probe $23(10 \mu \mathrm{M})$ for $30 \mathrm{~min}$, and further incubated with $\mathrm{NaHSO}_{3}(200 \mu \mathrm{M})$ for 30 min from the green channel; $(G)$ imaging of $(F)$ from the red channel; (I) overlay of $(\mathrm{G})$ and $(\mathrm{H})$; Scale bar: $100 \mu \mathrm{m}$.

\section{Conclusions}

In summary, we report a series of 1,2-cyclic sulfite diesters that: can be easily synthesized; are stable at room temperature; have tunable $\mathrm{SO}_{2}$ release profiles; and are well suited to study effects of enhanced intracellular levels of $\mathrm{SO}_{2}$ and duration of exposure to this reactive species. Together, we present superior alternatives to inorganic sulfites, the most commonly used $\mathrm{SO}_{2}$ donors. Due to the fundamental importance of redox regulation in cellular growth and survival, perturbation of redox homeostasis has emerged as a possible mechanism for the development of new therapeutics. ${ }^{[21]}$ Thus, reliably generating reactive oxygen, ${ }^{[22]}$ nitrogen $^{[23]}$ and sulfur species $\left.{ }^{[8 a}, 8 b, 8 \mathrm{e}\right]$ may have a range of applications including developing small molecule-based inhibitors of against bacteria such as Staphylococcus aureus, $\left.{ }^{[8,}, 22 \mathrm{e}\right]$ Mycobacterium tuberculosis ${ }^{[8 \mathrm{a}, 8 \mathrm{~b}, 22 \mathrm{a}, 22 \mathrm{~b}]}$ as well as cancer. ${ }^{[24]}$

\section{Experimental Section}

Synthesis and characterization data for all new compounds and assay protocols.

\section{Acknowledgments}

The authors thank IISER Pune and the Department of Biotechnology, Ministry of Science and Technology, India (DBT); Grant Number: BT/PR6798/MED/29/636/2012 for financial support. SM and KAP acknowledge research fellowships from
Council for Scientific and Industrial Research (CSIR) and University Grants Commission (UGC), respectively.

Keywords: Sulfur dioxide, Cyclic sulphite ester, Reactive sulfur species, sulfite

[1] a) M. H. Stipanuk, Annu. Rev. Nutr. 1986, 6, 179-209; b) T. P. Singer E. B. Kearney, Arch. Biochem. Biophys. 1956, 61, 397-409; c) W. Wang, B. Wang, Front. Chem. 2018, 6.

[2] a) Y. Zhao, T. D. Biggs, M. Xian, Chem. Commun. 2014, 50, 11788 11805 ; b) K. Shatalin, E. Shatalina, A. Mironov, E. Nudler, Science 2011, 334, 986-990.

[3] a) Z. Meng, G. Qin, B. Zhang, J. Bai, Mutagenesis 2004, 19, 465 468; b) W. Dröge, Phys. Rev., 82, 47-95.

[4] a) L. A. Komarnisky, R. J. Christopherson, T. K. Basu, Nutrition 2003 19, 54-61; b) C. S. Ough, E. A. Crowell, J. Food Sci. 1987, 52, 386 388.

[5] a) A. F. Gunnison, Food and Cosmetics Toxicology 1981, 19, 667 $682 ;$ b) E. Rencüzoğullari, H. B. İla, A. Kayraldiz, M. Topaktaş, Mutat. Res. 2001, 490, 107-112; c) X. Shi, J. Inorg. Biochem. 1994, 56 155-165.

[6] a) P. Bisseret, N. Blanchard, Org. Biomol. Chem. 2013, 11, 5393 5398 ; b) E. J. Emmett, M. C. Willis, Asian J.Org. Chem. 2015, 4, 602-611.

[7] a) H. Niknahad, P. J. O'Brien, Chem.-Biol. Interact. 2008, 174, 147154; b) Z. Meng, Y. Li, J. Li, Arch. Biochem. Biophys. 2007, 467, 291-296.

[8] a) S. R. Malwal, D. Sriram, P. Yogeeswari, V. B. Konkimalla, H. Chakrapani, J. Med. Chem. 2012, 55, 553-557; b) S. R. Malwal, D. Sriram, P. Yogeeswari, H. Chakrapani, Bioorg. Med. Chem. Lett. 2012, 22, 3603-3606; c) S. R. Malwal, M. Gudem, A. Hazra, H. Chakrapani, Org. Lett. 2013, 15, 1116-1119; d) S. R. Malwal, H. Chakrapani, Org. Biomol. Chem. 2015, 13, 2399-2406; e) K. A Pardeshi, S. R. Malwal, A. Banerjee, S. Lahiri, R. Rangarajan, H. Chakrapani, Bioorg. Med. Chem. Lett. 2015, 25, 2694-2697; f) K. A. Pardeshi, G. Ravikumar, H. Chakrapani, Org. Lett. 2018, $20,4-7$.

[9] a) M. J. Pena-Egido, B. Garcia-Alonso, C. Garcia-Moreno, J. Agric Food Chem. 2005, 53, 4198-4152; b) B. Garcia-Alonso, M. J. PenaEgido, C. Garcia-Moreno, J. Agric. Food Chem. 2001, 49, 423-429; c) D. Liu, H. Jin, C. Tang, J. Du, Mini Rev. Med. Chem. 2010, 10, 1039-1045.

[10] R. Kodama, K. Sumaru, K. Morishita, T. Kanamori, K. Hyodo, T. Kamitanaka, M. Morimoto, S. Yokojima, S. Nakamura, K. Uchida, Chem. Commun. 2015, 51, 1736-1738.

[11] J. J. Day, Z. Yang, W. Chen, A. Pacheco, M. Xian, ACS Chem. Biol. 2016, 11, 1647-1651.

W. Wang, B. Wang, Chem. Commun. 2017, 53, 10124-10127.

G. Fakha, D. Sinou, Molecules 2005, 10, 859-864

Z. Behzad, B. Tarifeh, Bull. Chem. Soc. Jpn. 2005, 78, 307-315

a) A. J. Williams, S. Chakthong, D. Gray, R. M. Lawrence, T. Gallagher, Org. Lett. 2003, 5, 811-814; b) R. Peters, D. F. Fischer, Org. Lett. 2005, 7, 4137-4140.

[16] D. F Shellhamer, D. T. Anstine, K. M Gallego, B. R. Ganesh, A. A Hanson, K. A. Hanson, R. D. Henderson, J. M. Prince, V. L. Heasley, J. Chem. Soc., Perkin Trans. 2 1995, 861-866.

[17] C. A. Bunton, P. B. D. de la Mare, P. M. Greaseley, D. R. Llewellyn, N. H. Pratt, J. G. Tillett, J. Chem. Soc. 1958, 4751-4754.

[18] a) K. Nymann, L. Jensen, J. S. Svendsen, Acta Chem. Scand. 1996 $50,832-841$; b) K. Nymann, J. S. Svendsen, Acta Chem. Scand. $50,832-841$; b) K.
1994, 48, 183-186.

[19] H. K. Garner, H. J. Lucas, J. Am. Chem. Soc. 1950, 72, 5497-5501.

[20] a) W. Chen, Q. Fang, D. Yang, H. Zhang, X. Song, J. Foley, Anal. Chem. 2014, 87, 609-616; b) Y. Sun, D. Zhao, S. Fan, L. Duan, R. Li, J. Agric. Food Chem. 2014, 62, 3405-3409; c) Y.-Q. Sun, J. Liu, J. Zhang, T. Yang, W. Guo, Chem. Commun. 2013, 49, 2637-2639; d) C. Wang, S. Feng, L. Wu, S. Yan, C. Zhong, P. Guo, R. Huang, X. Weng, X. Zhou, Sensors Actuators B: Chem. 2014, 190, 792-799; e) M.-Y. Wu, K. Li, C.-Y. Li, J.-T. Hou, X.-Q. Yu, Chem. Commun. 2014, 50, 183-185.

[21] a) A. Kumar, A. Farhana, L. Guidry, V. Saini, M. Hondalus, A. J. C. Steyn, Exp. Rev. Mol. Med. 2011, 13, 1 (e39); b) G. T. Wondrak, Antioxidants Redox Signal. 2009, 11, 3015-3069.

[22] a) P. Tyagi, A. T. Dharmaraja, A. Bhaskar, H. Chakrapani, A. Singh Free Radic. Biol. Medicine 2015, 84, 344-354; b) A. T. Dharmaraja M. Alvala, D. Sriram, P. Yogeeswari, H. Chakrapani, Chem. Commun. 2012, 48, 10325-10327; c) A. T. Dharmaraja, H. Chakrapani, Org. Lett. 2014, 16, 398-401; d) A. T. Dharmaraja, T. K. Dash, V. B. Konkimalla, H. Chakrapani, Med. Chem. Comm 2012, 3, 219 - 224; e) V. S. Khodade, M. Sharath Chandra, A. Banerjee, 
S. Lahiri, M. Pulipeta, R. Rangarajan, H. Chakrapani, ACS Med. Chem. Lett. 2014, 5, 777-781.

$[23$

a) K. Sharma, A. lyer, K. Sengupta, H. Chakrapani, Org. Lett. 2013

15, 2636-2639; b) K. Sharma, K. Sengupta, H. Chakrapani, Bioorg

Med. Chem. Lett. 2013, 23, 5964-5967; c) A. T. Dharmaraja, G.

Ravikumar, H. Chakrapani, Org. Lett. 2014, 16, 2610-2613.
S. Li, R. Liu, X. Jiang, Y. Qiu, X. Song, G. Huang, N. Fu, L. Lin, J. Song, X. Chen, H. Yang, ACS Nano 2019, 13, 2103-2113. 


\section{COMMUNICATION}

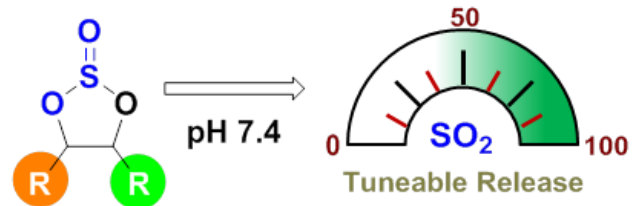

Although sulfur dioxide $\left(\mathrm{SO}_{2}\right)$ finds widespread use in the food industry as its hydrated form, sulfite, a number of aspects of $\mathrm{SO}_{2}$ biology remain to be completely understood. Among the tools available for intracellular enhancement of $\mathrm{SO}_{2}$, most suffer from poor cell permeability and a lack of control over $\mathrm{SO}_{2}$ release. We report 1,2-cyclic sulfite diesters as a new class of reliable $\mathrm{SO}_{2}$ donors that dissociate in buffer through a nucleophilic displacement to produce $\mathrm{SO}_{2}$ with tuneable release profiles. We provide data in support of the suitability of these $\mathrm{SO}_{2}$ donors to enhance intracellular levels of $\mathrm{SO}_{2}$ at an efficiency superior to sodium bisulfite, the most commonly used $\mathrm{SO}_{2}$ donor for cellular studies.

\section{Sulfur dioxide donors*}

Satish R. Malwal, Kundansingh A.

Pardeshi, Harinath Chakrapani 